The value of including Global Health in the training of health professionals

Elizabeth Molyneux ${ }^{1}$ and Bernadette $\mathrm{O}^{\prime}$ Hare $^{, 1,2,3}$

${ }^{1}$ Department of Paediatric and Child Health, College of Medicine, Blantyre, Malawi

${ }^{2}$ Global Health Implementation, College of Medicine, Blantyre, Malawi \& St Andrews, Scotland.

RCPCH Advisor for East Africa

Conflict of interest: none

Corresponding author: emmolyneux@gmail.com

Words: 1141 


\section{What is Global Health?}

We live in a 'global village', face global climate changes, global financial downturns and global epidemics, and need global policies. So what is global health?

Global Health has grown out of public health and international or tropical health. Whereas public health is largely focussed on preventive care and is usually within a country or a community, and international health is mainly about the health problems of low income or middle income countries and the bi-national assistance given to them. Global Health deals with those health issues that may affect many countries, irrespective of their level of development. It includes both clinical and preventive health care and goes beyond the traditional health specialities to include a wider range of disciplines such as economics, biomedical engineering, city planning, social science and policy making. It addresses not only problems such as epidemics (eg HIV, influenza) but also health issues resulting from urbanisation, climate change, tobacco use, micronutrient deficiencies, and other challenges to well being(figure 1).

Global refers to the breadth of the problem rather than a geographical location. Global Health adopts a philosophy of mutual respect, making use of real partnerships through which experience and knowledge are pooled to the benefit of all parties. It is not a one-way flow of ideas and effort(1). Above all Global Health is premised on the need for universal and equitable provision of health care.

\section{Why is Global Health important?}

Nations are interdependent economically. Travel and rapid communications have changed the exposure to environments and diseases that influence the health of peoples. All paediatricians should be aware of the circumstances in which most of the children in this world live(Table 1). Migration and cross border movements generate minority groups who may have health needs not anticipated by existing health systems. 
Most UK trainees will practise paediatrics in the UK, where the population is increasingly diverse.

Throughout their working lives paediatricians will encounter children newly arrived from overseas or who have visited family overseas. A UK paediatrician will need to be familiar with the global burden of disease and the first steps to take in the diagnosis and management of these illnesses. They will need to appreciate the cultural context of their patients. As health professionals and members of a globalised world they will want to advocate for health for all children regardless of where they live, and to do this they will need to understand the economic and political causes of poverty and ill health.

\section{How does Global Health experience benefit the individual health trainee?}

Learning Global Health ideally involves spending at least some time in a health system other than

your own. Being exposed to a different culture, coming close to poverty and experiencing how other health workers manage in less than ideal circumstances - all of these can be life changing. Learning to respect another point of view, to take responsibility, to teach, to be taught, and to make new friends will inform how a health professional will approach problems in their own health service.

Over the last 30 years many students and postgraduate trainees have joined us where we work in Africa; many have said that the experience has reminded them of why they went into medicine, has re- kindled their enthusiasm for clinical care and focussed what they want to do in the future.

We have watched trainees grow in confidence, maturity and ability. They develop an increasing awareness of global needs and learn a respect for the wealth of traditional knowledge and social good displayed by the people among whom they worked. Spending time in an unfamiliar setting with unfamiliar diseases and drugs, and trying to communicate in a foreign language, are challenges that are initially bewildering and humbling. The experience makes a trainee sympathetic to the difficulties faced by foreign staff in any health service. 


\section{How does training in Global Health benefit the National Health Service?}

In a recent all-party parliamentary report on Global Health chaired by Lord Crisp and Meg Hillier MP, a spokesperson for the Sheffield Health and Social Care NHS Foundation Trust is quoted as saying 'Members of staff return from international work highly motivated, with increased work ethic and renewed vocation for the NHS. They are more adaptable and open-minded, innovative in their approach to service delivery and capable of leading change.'(2).

The Tropical Health and Education Trust (THET) promotes links between NHS hospitals and hospitals in developing countries and reports enormous benefit to the individuals, the NHS hospitals and the overseas receiving hospitals. There are many 'twinnings' that have grown out old friendships, previous electives or through charities such as World Child Cancer. Most members of staff are more flexible and better at leading change when they have worked in one of these programmes.

\section{Does the local ('receiving') hospital benefit from visiting trainees?}

The volunteers are usually idealistic, enthusiastic and hard working. They contribute to clinical care, to teaching, to audits and research. Their recent exposure to College examinations may help their colleagues facing similar hurdles. Commonly friendships are established that last many years, and that may be the basis for later collaborations.

It would be good to see more opportunities for trainees in the receiving units to experience a different health service, with the same benefits to their own personal and professional development.

\section{What is the future for global child health training in the UK?}

Goenka and colleagues write in this journal about the opportunities and value of training in global health for paediatricians and clearly articulate pathways for young paediatricians to follow in order to gain clinical and research experience overseas(3). There is also a growing consensus that all trainees in all specialities need a minimum awareness of global health issues. This should build on 
proposed global health learning outcomes recommended for UK undergraduates. Global health has resulted in a shift of focus towards the determinants of health as well as the systems in which healthcare is sought. The teaching of this will require a cross-disciplinary approach as a broad skillset is required to understand health in a globalised world(4). There are no estimates of the relative contribution of the different determinants of health but it is thought that the socioeconomic determinants of health may account for up to $70 \%$ of health outcomes in children. In order to map the training priorities in global health, we could use a pathway of the global policies which may impact health, from decisions made distally to those made by the family(figure 1).

A recent study reviewed the content of the curricula of 11 UK post-graduate colleges and found that six of the eleven curricula contained global health competencies. The authors recommend that core global health competencies should be consistent across all specialities(5). We agree that core global health training should be common to all specialities and should build on the cross-disciplinary approach suggested for the undergraduate curriculum with a specific module pertaining to health in children. In view of the broad range of expertise required, it would be ideal if these courses could be developed at college level. 


\section{References}

1. Koplan JP, Bond TC, Merson MH, Reddy KS, Rodriguez MH, Sewankambo NK, Wasserheit JN for the Consortium of Universities for Global Health Executive Board Towards a common definition of global health. Lancet 2009; 373: 1993-95.

2. Improving Health at Home and Abroad. How overseas volunteering from the NHS benefits the UK and the world. A report on overseas volunteering and international partnerships by the All-Party Parliamentary Group on Global Health www.appg-globalhealth.org.uk (accessed July 2013).

3. Goenka A, Magnus D, Carrol ED, Rehman T, Spillman I, Williams B, Long A, Allen S. Child health in low-resource settings: pathways through UK paediatric training. Arch Dis Child 2013;

4. Rowson M, Smith A, Hughes R, Johnson O, Maini A, Martin S, et al. The evolution of global health teaching in undergraduate medical curricula. Globalization and health [Internet]. 2012 Jan [cited $2013 \mathrm{Jul} 14] ; 8(1): 35$. Available from:

http://www.globalizationandhealth.com/content/8/1/35 (accessed July 2013).

5. Hall J, Brown C, Pettigrew L, Malik A, Watson J, Topiwala A, et al. Fit for the future? The place of global health in the UK's postgraduate medical training: a review. JRSM short reports [Internet]. 2013 Mar [cited 2013 Jun 19];4(3):19. Available from: http://www.pubmedcentral.nih.gov/articlerender.fcgi?artid=3616298\&tool=pmcentrez\&ren dertype=abstract (accessed July 2013). 
Table 1 Children of the World - a few facts.

\section{CHILDREN OF THE WORLD}

A few facts

On this globe there are 2.2 billion children: of whom 1.9 million live in Low Income or Middle Income Countries

1 billion live in poverty

640 million (1 in 3) are without shelter 400 million (1 in 5) with no safe water 270 million (1 in 7) no access to health 11 million are not in school

Three quarters of the children who survive on $<1$ US\$ live in rural area Three quarters of all the malnourished children live in rural areas

Half the world live in cities and towns - 1 in 3 live in slums

The widest gap between rich and poor is in the richest countries.

Source: Poverty Facts and Stats - Global Issues Human Development Programme. UNDP November 27 2007, page 25 www.globalissues.org > Issues (Accessed July 2013) 
Figure $1 \mathrm{Global}$ Influences on health

POSITIVE - socioeconomic determinants Globalization of trade

Openness to trade may lift many out of poverty

Agricultural subsidies $\rightarrow$ lowers world prices, may positively impact importers

Globalisation of services

Countries may decide which services to open and competition may improve services

Globalisation of capital

Increased foreign direct investment

Globalisation of information

Governments and transnational companies may be held to account. Social media may

allow civil society mobilisation

Globalisation of people

Remittance/skills from rich to poor countries
Direct influences on Health

General Agreement on Trade

in Services (GATs) -

healthcare services open to

international markets.

Trade Related Intellectual

Property (TRIPs) agreements may limit access to affordable medication.

Tobacco, alcohol and processed food more widely available.

Movement of health professionals across borders. Improved health literacy
NEGATIVE - socioeconomic determinants Globalization of trade

Lower import taxes may reduce revenue to spend on social goods. Agricultural subsidies may negatively impact exporters of those goods. Escalating tariffs on processed goods and non-tariff barriers may impact exporters.

TRIPs agreement may limit access to affordable new technology

Globalisation of services

Water and sanitation services open to investors may not be sufficiently regulated

Globalisation of capital

May Increase capital flight to tax havens Speculation in commodity \& food markets

Globalisation of people

Poor countries may lose skilled workforce

\section{Country resources/GDP}

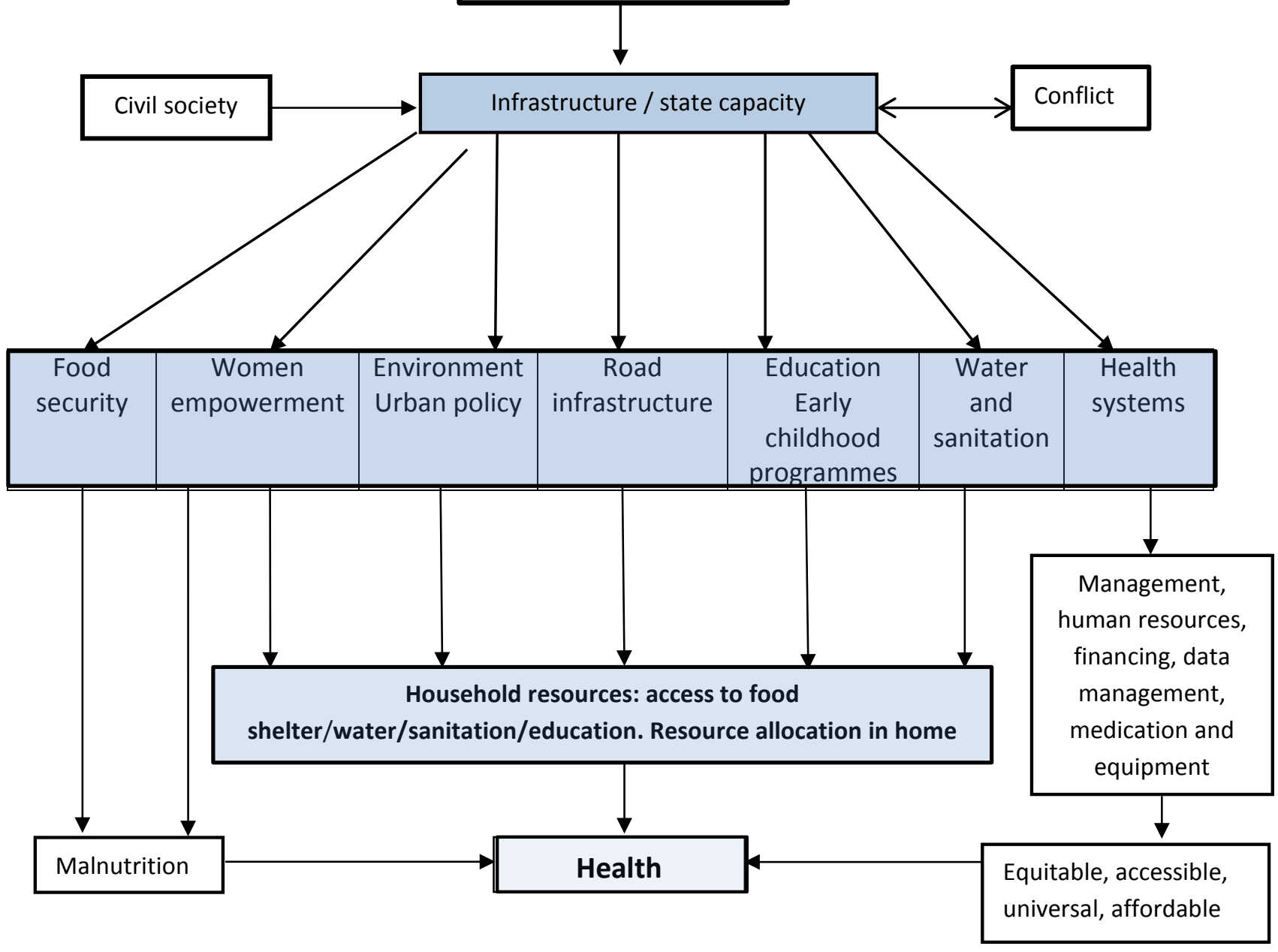

